\title{
La reanudación de los intercambios entre el Mediterráneo Oriental y el Occidental después de la crisis del siglo XII AC. Un fragmento de cerámica a torno pintada del Heládico/Minoico Final IIIC en Huelva (1150-1050 AC)
}

\section{The resumption of the exchanges between the Eastern and Western Mediterranean after the crisis of the XIIth century BC. A fragment of Late Helladic/Minoan IIIC wheel-made painted pottery in Huelva (1150-1050 BC)}

Francisco Gómez Toscano ${ }^{1}$

Alfredo Mederos Martín ${ }^{2}$

Recibido: 15-02-2018

Aceptado: 12-09-2018

\begin{abstract}
Resumen
Resultado de una excavación de urgencia en la calle Palos de la Frontera de la ciudad de Huelva a mediados de los años setenta del siglo XX, se localizó un fragmento de crátera del Geométrico Medio II. Años después identificamos una cerámica a torno pintada que por su grosor parece pertenecer a una jarra de transporte que contenía algún tipo de bebida. Puede tratarse de una producción filistea del Heládico Final IIIC Early 2 que continuaron durante el Heládico Final IIIC Middle, 1153-1070 AC. Otra alternativa sería una jarra de transporte del Minoico Final IIIC, 1190-1070 AC. Esta importación sugiere la reanudación de la ruta entre el Mediterráneo Oriental, Fenicia, Chipre y Creta, con el Mediterráneo Occidental después de la crisis de los Pueblos del Mar en la primera mitad del siglo XII a.C.
\end{abstract}

Palabras clave: Península Ibérica, Huelva, Bronce Final, cerámica a torno pintada.

\begin{abstract}
As a result of a salvage excavation in Palos de la Frontera street in the city of Huelva in the mid-seventies of the 20th century, a fragment of a Middle Geometric II crater was located. Years later we identified a wheel-made painted pottery that due a its thickness seems to belong to a transport jar that contained some type of drink. It may be a Philistine production of the Late Helladic IIIC Early 2 that continued during the Late Helladic IIIC Middle, 11531070 BC. Another alternative would be a transport jar of the Late Minoan IIIC, 1190-1070 BC. This import suggests the resumption of the route between the Eastern Mediterranean, Phoenicia, Cyprus and Crete, with the Western Mediterranean after the crisis of the Peoples of the Sea in the first half of the 12th century BC.
\end{abstract}

Key words: Iberian Peninsula, Huelva, Late Bronze Age, wheelmade painted pottery.

1 Departamento de Historia I, Universidad de Huelva, fgomez@uhu.es, ORCID: https://orcid.org/0000-0002 $5721-4056$
2 Departamento de Prehistoria y Arqueología, Universidad Autónoma de Madrid, alfredo.mederos@uam.es, ORCID: https://orcid.org/0000-0002-0036-7940 


\section{INTRODUCCIÓN}

Durante la revisión que hicimos hace bastantes años uno de nosotros de los materiales que acompañaban al fragmento de crátera ática del Geométrico Medio II de la calle Palos de la Frontera 21-23 de Huelva (Gómez Toscano, 1990), en cuya monografía también colaboramos como dibujante (del Amo, 1976: 5), junto al cabezo de la Esperanza y muy próximo a la calle Méndez Núñez-plaza de las Monjas (González de Canales et alii, 2004; Mederos, 2006), observamos entre ellos un interesante fragmento cerámico en los fondos del Museo Provincial y comprobamos el lugar de su hallazgo y en qué circunstancias fue documentado. Según su excavador (del Amo, 1976: 38, 40, 39 fig. 8,41 fig. 9) se trataba bien de un fragmento que formaba parte de un conjunto de cerámicas protohistóricas de los siglos VII-V a.C., que incluye cerámicas fenicias como platos de engobe rojo o morteros, selladas por una factoría de salazones de pescado romana pues aparecieron bajo el muro de la pileta 3 y el muro exterior, aunque sin descartar que fuese parte de un relleno de tipo antrópico más reciente posterior a la

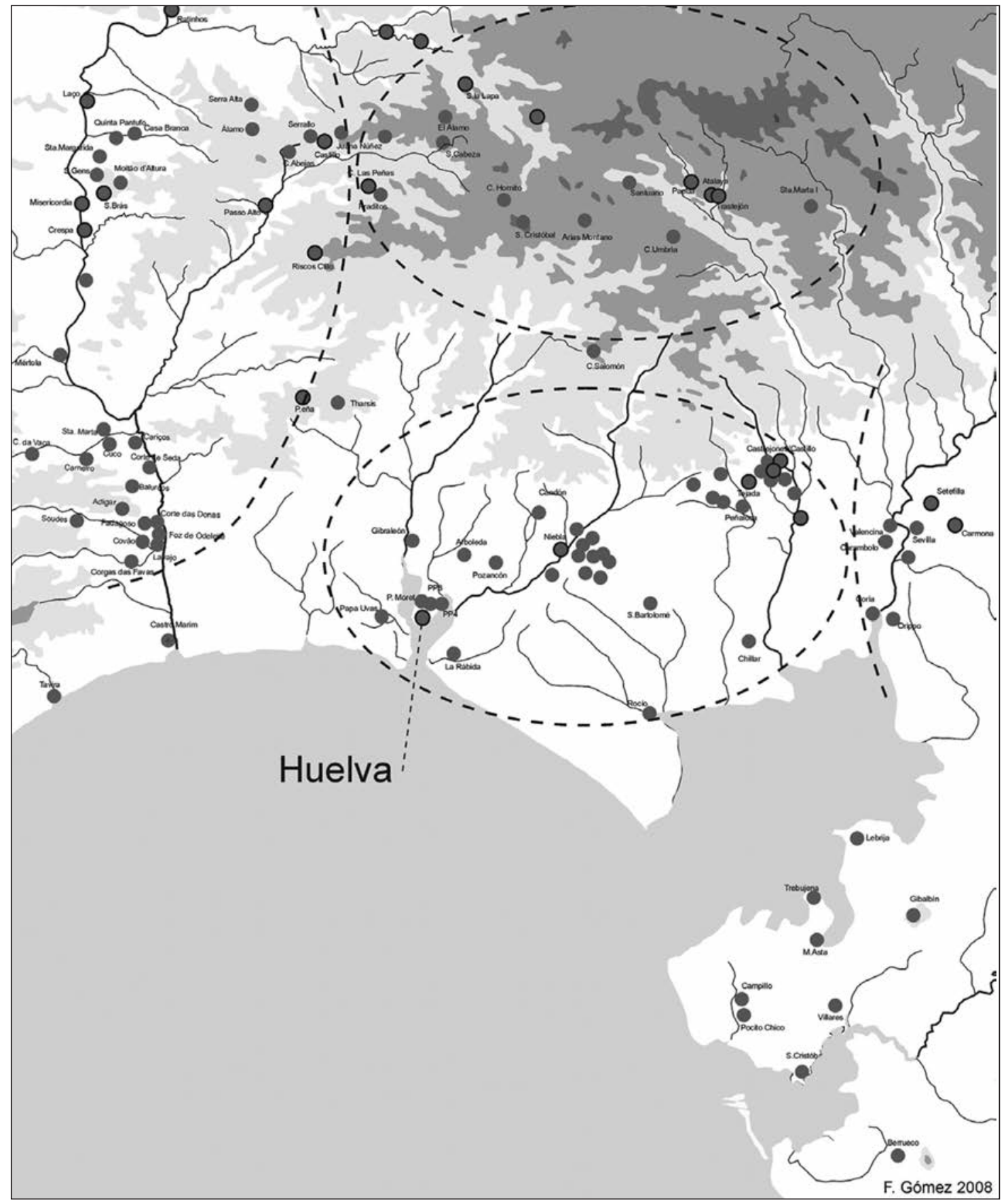

Figura 1. Ubicación del poblado de Huelva en el Suroeste de la Península Ibérica durante el Bronce Final, en relación con otros poblados contemporáneos (Gómez Toscano y Fundoni, 2010-11: 27 fig. 1). 
factoría, depositado entre dos muros de la zona donde se abrieron las piletas de salazón de la factoría romana excavada en la década de los setenta. Como indica del Amo (1976: 25) se reconstruyó una planta de la factoría después de que una pala mecánica hiciese varias zanjas para la cimentación de un edificio. Por esta razón, en el Museo onubense el fragmento inédito figura en una ficha que lo identifica, con interrogantes, como un vaso islámico porque no se encontraron para- lelos claros para la forma del vaso, al no presentar un borde y un perfil característicos (fig. 1-2).

La presencia también descontextualizada en estos niveles alterados por las obras de cimentación y la previa instalación de una factoría romana de salazones (del Amo, 1976: 40-42, 41 fig. 9/9), de un fragmento de crátera del Geométrico Medio II (Shefton, 1982: 342 n. 11, lám. 30a) o píxide, pues algunos autores consideran que el dibujo es incorrecto y debía estar

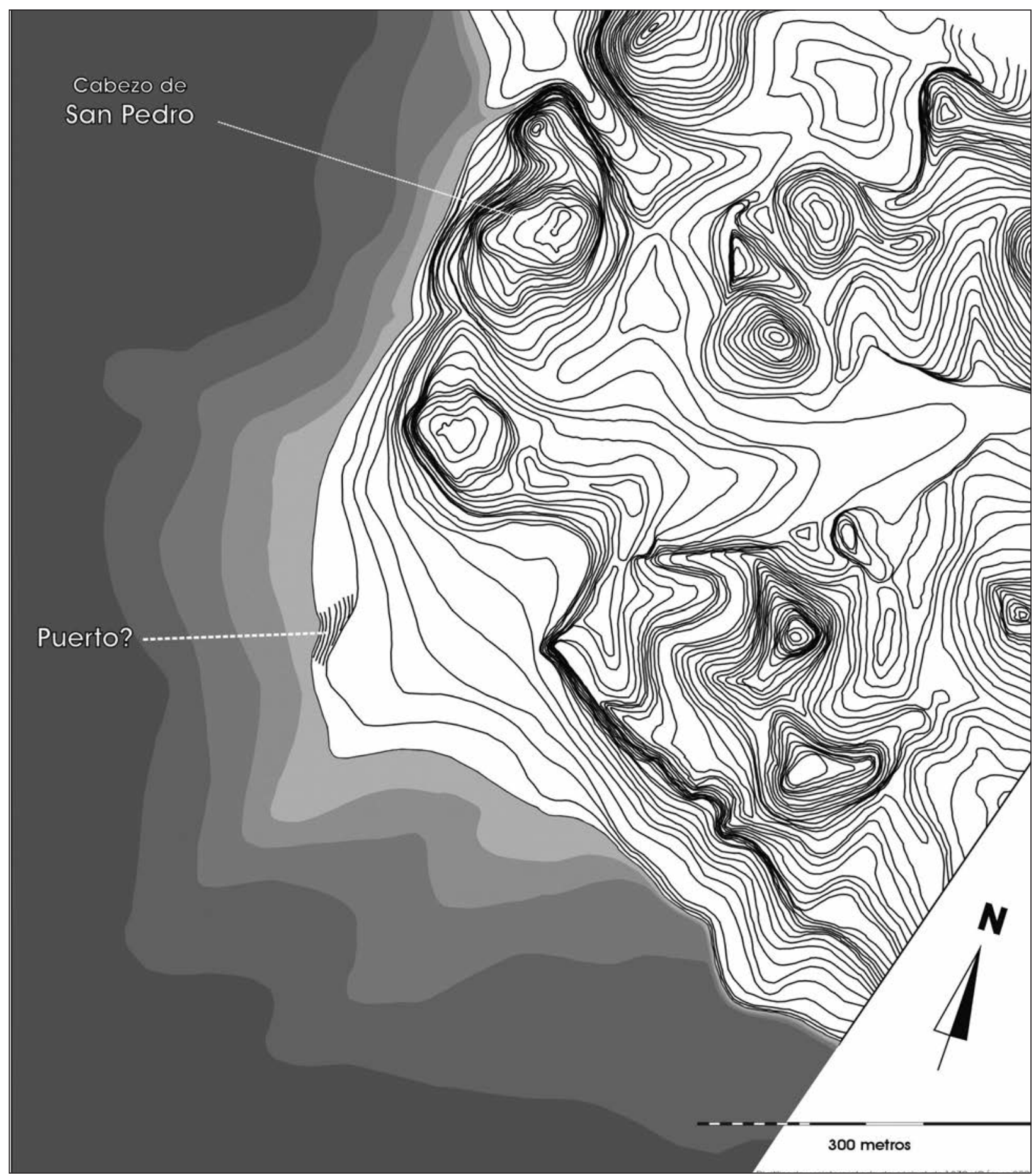

Figura 2. Cabezos del Bronce Final ocupados en Huelva y ubicación del posible puerto, a partir del plano topográfico de 1870 y propuesta de reconstrucción de la línea de costa (Gómez Toscano, 2012: 313 fig. 3). 
orientado hacia adentro para recibir una tapadera en la ranura (Coldstream, 1982: 369; Cabrera, 1988-89: 44, 87 fig. 1/1), eclipsó el estudio de otras cerámicas de este contexto. La reconstrucción del vaso, a partir de la curva conservada, muestra un diámetro que no puede ser inferior a $45 \mathrm{~cm}$, acorde con el espesor de su pared si fuese una crátera (fig. 3a-3c).

El debate generado por este fragmento que fue entonces la cerámica egea más antigua conocida en la Península Ibérica, incluso mencionado para fijar el inicio de la colonización fenicia coincidiendo con Tiro III (Torres, 1998: 54), comenzó porque fue inicialmente clasificado como Subgeométrico según comunicó Villard a del Amo (1976: 40-42), o Geométrico ático del 750 a.C. (del Amo, 1976: 43 nota externa), para poco después ser asignado a una crátera del Geométrico Final I, entre el 760-730 a.C. (Rouillard, 1977: 397-399, 397 fig. 169, 418 lám. 15/1), hasta su identificación como del Geométrico Medio II (Shefton, 1982: 342 n. 11, lám. 30a; Coldstream, 1982: 369). Todo ello hizo que no se prestase más atención a este fragmento por parte de los investigadores españoles y extranjeros a los que el entonces director del Museo mostró, según se nos dijo, permaneciendo olvidado durante mucho tiempo.

Por nuestra experiencia en la excavación de Tell Abu Hawam, en la bahía de Haifa, Israel (Herrera y Gómez Toscano, 2004), lo identificamos por sus características formales como una pieza egea del Heládico Final III, pues parece tratarse de un vaso cerrado conocido como jarra de estribo, una stirrup jar de tamaño medio a grande a juzgar por el grosor de la pared de la pieza, que no es típicamente micénico por las particularidades de la pasta y su decoración, pero semejante a otros ejemplares conocidos en el asentamiento israelí relacionados allí con el Minoico Final III (Balensi, 2004). En la década de los noventa esta filiación fue confirmada por colegas del Institute Courby de la Universidad de Lyon, a los cuales agradecemos su deferencia.

\section{El Bronce Final II en Huelva}

Aunque aún no se ha localizado un estrato intacto del Bronce Final II en Huelva, durante la excavación del área 3 , corte A-1, en el cabezo de la Esperanza, aparecieron cerámicas que habían sido desplazadas desde su lugar de origen o deposición en diferentes procesos postdeposicionales. De este sector proceden dos fragmentos a mano con superficies muy bien bruñidas (fig. 5/1-2) de los niveles I-II (Belén, Fernández-Miranda y Garrido, 1977: 270, 272 fig. 136/6, 280, 278 fig. 140/3), y otros dos muy toscos de apariencia panzuda del nivel III más profundo (fig. 5/3-4) (Belén, Fernández-Miranda y Garrido, 1977: 285, 286 fig. 145/5-6). Además, otros dos proceden de una recogida superficial en el cabezo de la Esperanza según informe de Juana Bedia (fig. 5/6-7). Igualmente, también incluimos un fragmento decorado con impresiones cortas y posibles incisiones o impresiones formando triángulos con vértice hacia abajo de tradición de Cogotas I (fig. 5/5) recogido en las escombreras de la marisma de Huelva hace unos años por Leonardo Serrano, y que fue depositado en su día por uno de nosotros en el Museo Provincial de Huelva (Gómez Toscano y Campos, 2001: 113, 116 y 2008: 130 fig. 6). Por otra parte, entre las cerámicas recuperadas sin contexto de Plaza de las Monjas-Méndez Núñez (González de Canales et alii, 2004: 108, 194-195, lám. 34/16-17; Mederos, 2006: 168), existen cerámicas similares a los cuencos con carena baja y paredes relativamente finas (fig. 5/1-2) (fig. 4-5).

Estas cerámicas muestran las características de una fase de transición entre mediados del II Milenio y los inicios del Horizonte Formativo del Bronce Final de Huelva, hacia el 1200 AC (Gómez Toscano, 2008: 93 y 2013: 88 fig. 2), el Bronce Reciente A (Martín de la Cruz, 1989) o el final del Bronce Final IIB, 1225-1150 AC e inicios del Bronce Final IIC, 1150-1050 AC (Mederos, 1997: 77 tabla 2). Ya se ha planteado que de momento no hay contextos claros en la Península Ibérica de cerámicas de Cogotas I durante el Bronce Final IIC 1150-1050 AC, aunque no descartamos una pervivencia hasta ca. 1100 AC (Mederos, 2012: 101-102 tabla 3).

\section{El FRAgMento CERÁMico PINTAdo de la CAlle Palos de Huelva}

El fragmento cerámico a torno procedente de la antigua calle Palos, 20-27, se corresponde probablemente con una jarra de estribo o stirrup jar. Se conserva el arranque del cuello, con pasta más fina y parte de la espalda, donde suele ubicarse la decoración. Como presenta un mínimo de dos triángulos rellenos, uno de ellos bastante completo cabe presumir que se conserva buena parte de la espalda (fig. 6-7).

Los dos triángulos rellenos conservados, uno de ellos incompleto, tangentes por uno de sus vértices del lado menor, responderían a un esquema conformado por una serie de triángulos alineados y centralizados por el lado más corto alrededor de un falso cuello en la zona central superior del vaso, de donde también partirían las dos asas verticales típicas unidas o soportadas por el falso cuello.

Ese falso cuello estaría cerrado por arriba con una terminación en arcilla redondeada con función y forma de tapón que, tal vez, se decoraría con una espiral simple o con círculos concéntricos formados por finas líneas, según hemos desarrollado en el dibujo como posible alternativa. No hemos dispuesto en 

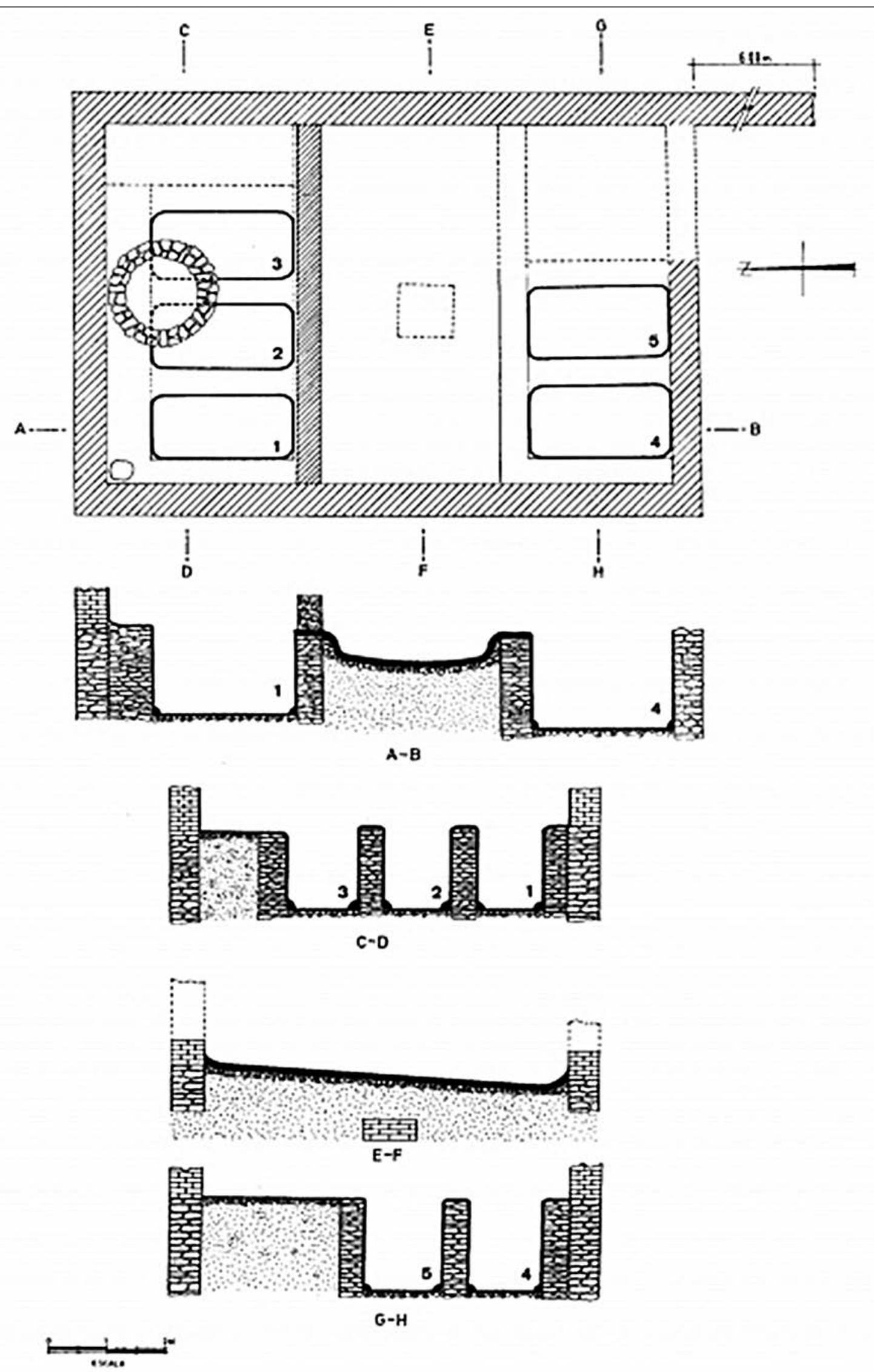

Figura 3a. Factoría de salazones romanas de la calle Palos de la Frontera, 21-23, con la pileta 3 bajo la cual apareció el fragmento del Geométrico Medio y el fragmento a torno pintado (del Amo, 1976: 26 fig. 2). 


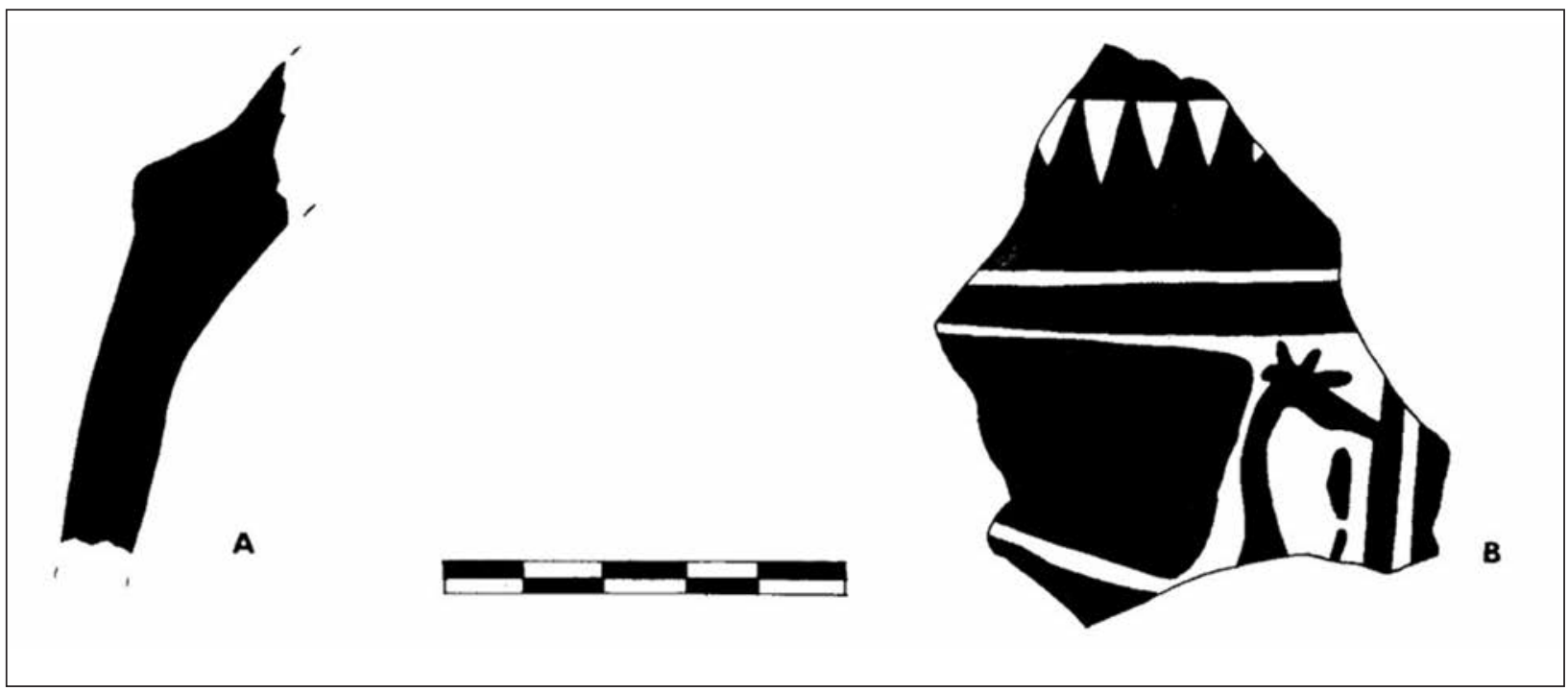

Figura 3b. Dibujo como crátera del fragmento del Geométrico Medio II (Rouillard, 1977: 397 fig. 169).

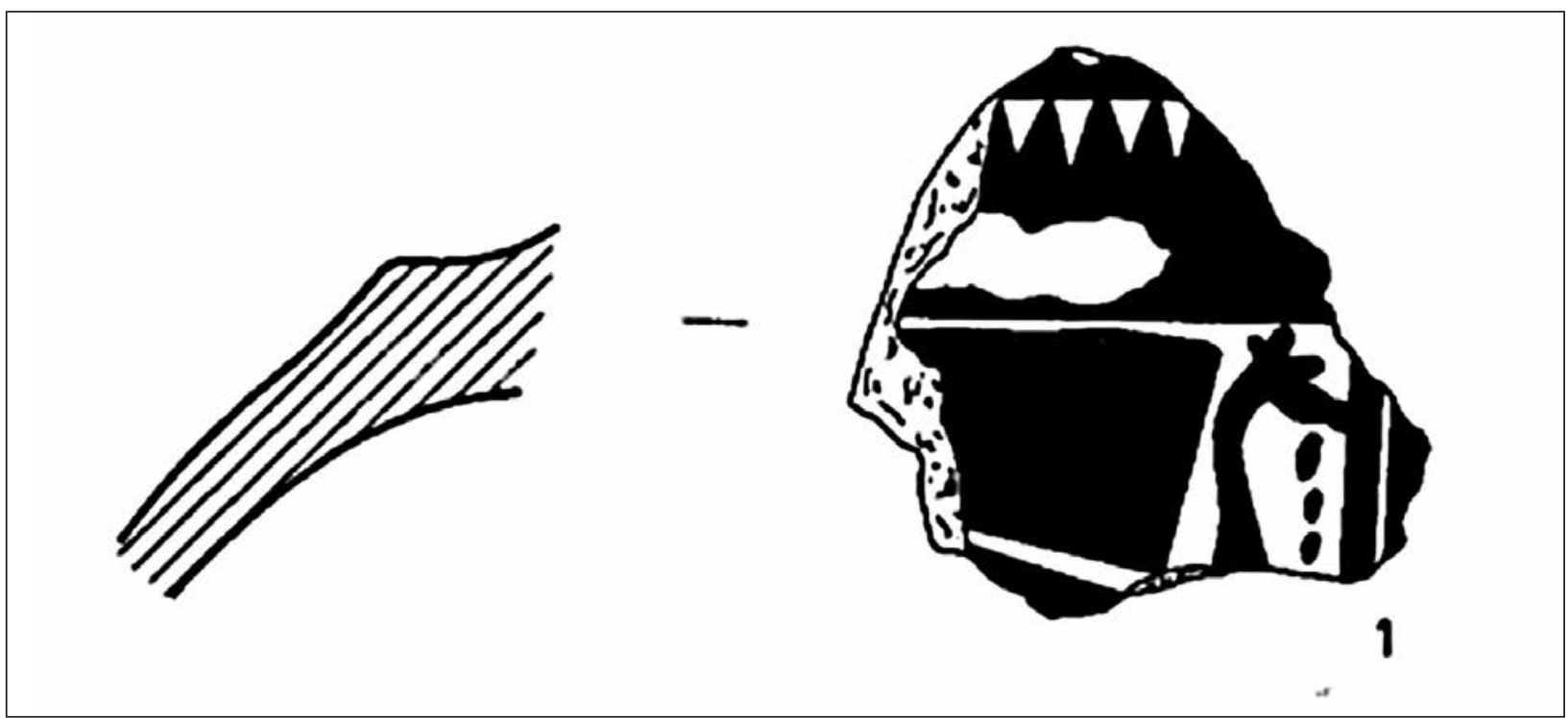

Figura 3c. Dibujo como píxide del fragmento del Geométrico Medio II (Cabrera, 1988-89: 87 fig. 1).

ese dibujo los dos posibles triángulos rellenos con pintura que podrían localizarse en el lugar de donde arrancarían las dos asas horizontales, ya que precisamente éstas impedirían acomodar los triángulos pintados en esos lugares.

Esos triángulos rellenos de pintura adosados al primer círculo que se sitúa en la zona más baja del falso gollete, los cuales centralizan el esquema como una estrella radial según se ha dicho, se acompañaron con una línea o trazo paralelo a los dos lados más largos de cada triángulo, junto con más de veinte trazos pequeños formando una especie de festón o plumeado colgante irregular.

En conjunto, visto desde arriba, el tema sería el de una estrella con puntas radiadas desde el citado falso cuello, cuyo número de ellas estaría limitado por el espacio disponible resultante tanto de la colocación en su lugar de las dos asas como del pitorro vertedor típico de las jarras de estribo, generalmente algo descentralizado este último, aunque relativamente enfrentado perpendicularmente a la línea de las asas.

En el caso de este motivo vegetal aplicado entre los triángulos y la línea quebrada del festón, se trata de un trazo vertical relacionado con el tallo de una palma donde en su extremo superior, además de cuatro pequeños trazos rectos enfrentados dos a dos e inclinados hacia el tallo, aparecen dos hojas lanceoladas combadas sobre sí mismas y, por debajo de ellas, otras dos que terminan en forma de volutas, las cuales intentan ser simétricas a ambos lados del trazo central y se enroscan en espiral. 


\section{Cabezo de la Esperanza (Huelva)}

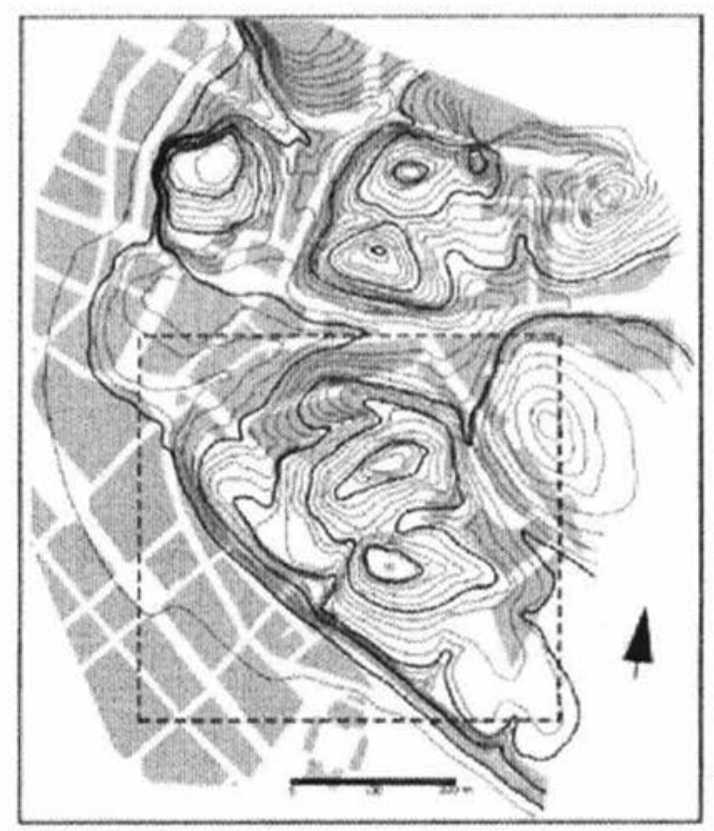

\section{Zona ampliada abajo}

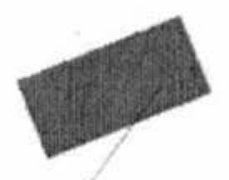

Localización aproximada del Área Tres.

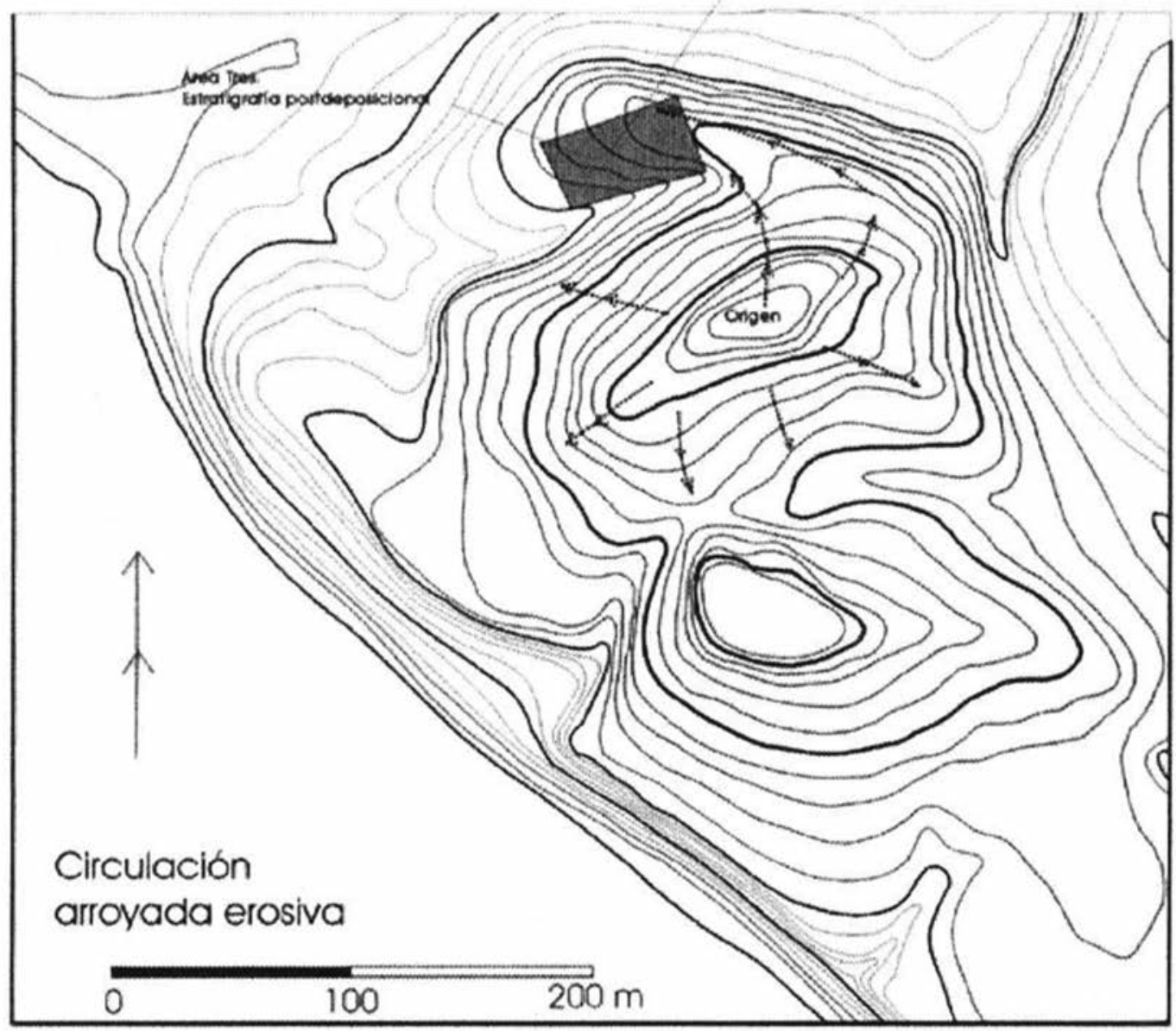

Figura 4. Ubicación del Cabezo de la Esperanza entre los cabezos de Huelva y emplazamiento del área 3, corte A-1, de donde proceden cerámicas de un momento avanzado del Bronce Final II (Gómez Toscano et alii, 2007: 164 fig. 6). 


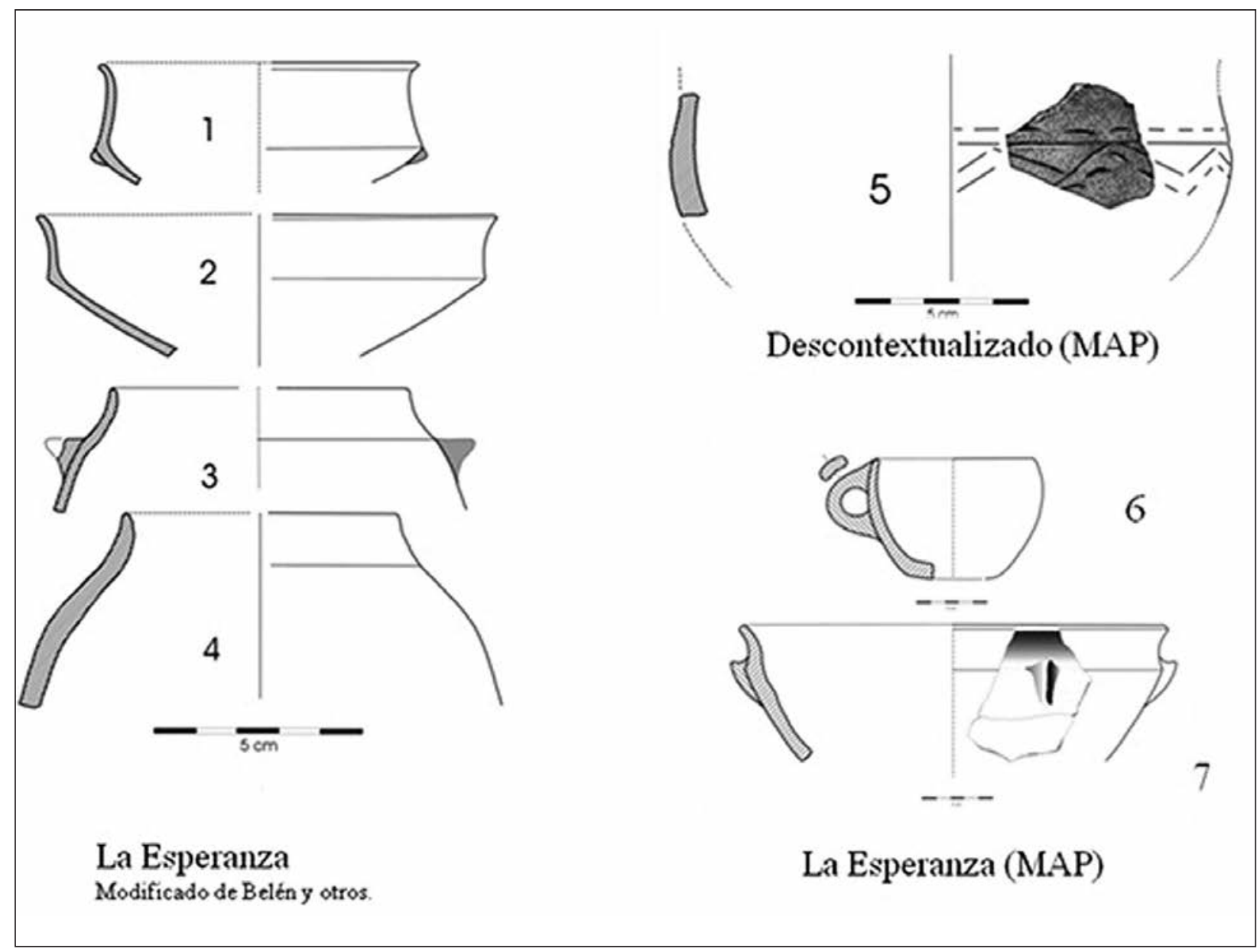

Figura 5. Cerámicas bruñidas y con decoración de tradición de Cogotas I del Bronce Final IIC u Horizonte Formativo procedentes del Cabezo de la Esperanza, depositadas en el Museo Arqueológico Provincial de Huelva.

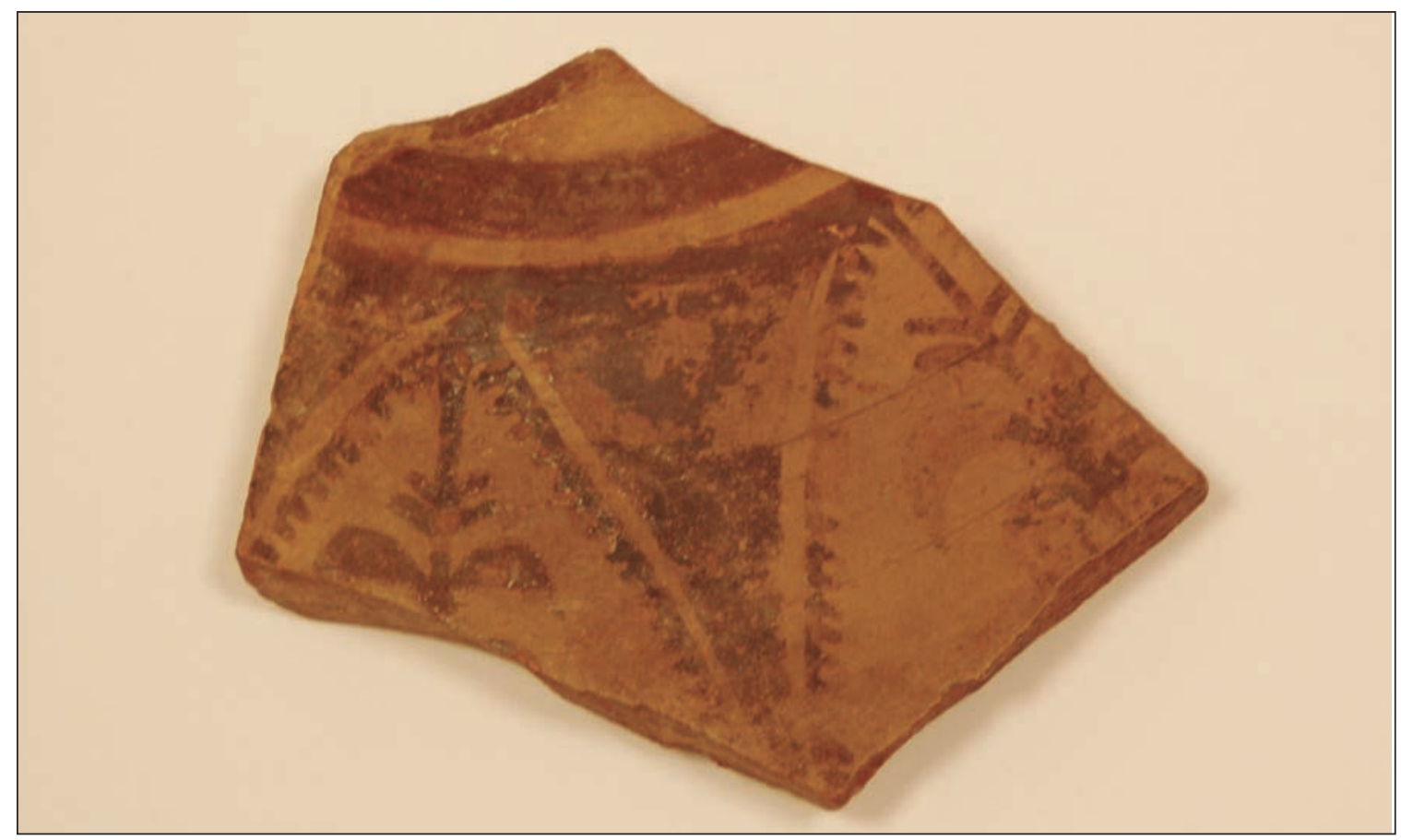

Figura 6. Fragmento cerámico a torno con decoración pintada de la calle Palos de la Frontera, 21-23, Huelva. 

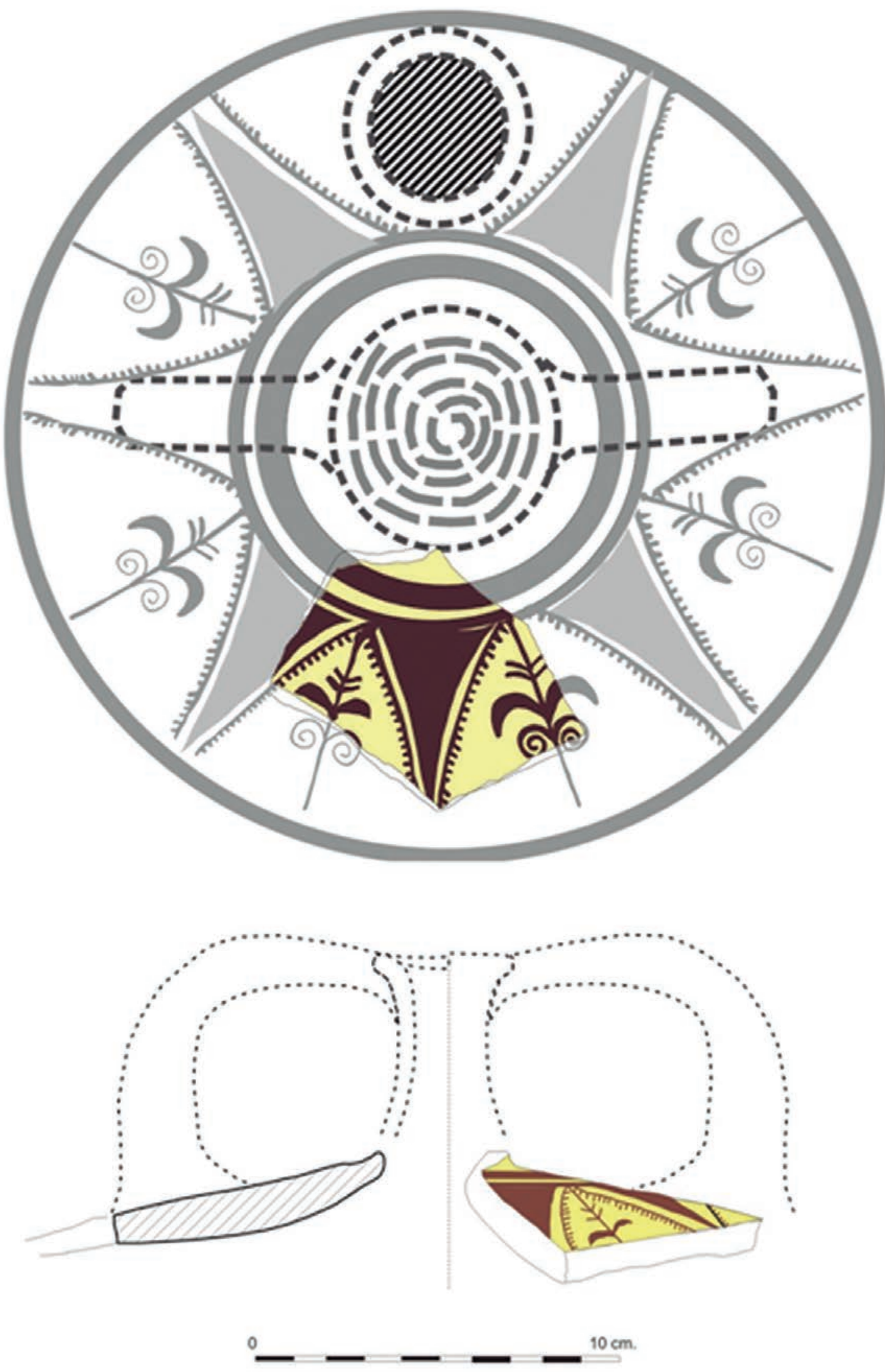

Figura 7. Propuesta de reconstrucción de la cerámica a torno con decoración pintada como una jarra de transporte o stirrup jar. 
El motivo vegetal entre los triángulos responde a un motivo típico de la cerámica minoica de flores de lily, con un pedículo que no se conserva, dos sépalos en forma de voluntas, dos pétalos lanceolados y cuatro filamentos de estambres dibujados enfrentados en parejas de dos. Estos motivos aparecen desde el Minoico Medio IIIB, y están muy generalizados desde el Minoico Final II (Niemeier, 1985: 59 fig. 18, 61 fig. 19; Müller, 1997: 150 fig. 80), aunque en el ejemplo de Huelva las 4 anteras de los estambres -anthers of stamens-, típicos de esta flor (Müller, 1997: 149 fig. 79), están más esquematizadas y enfrentadas dos y dos.

En el Mediterráneo Central esta constatada la presencia una jarra de estribo o stirrup jar del Minoico Final IIIC que tiene un acabado también en matt painted (Nigro, 2016: 350, 352 fig. 13), que se incluye en la fase Moyta IIB, entre el 1400-1250 AC, si bien el Minoico Final IIIC se considera que abarca entre el 1190-1070 AC (Warren y Hankey, 1989: 169). Otro fragmento de copa o taza de Torre Castelluccia (Puglia, Italia), inicialmente atribuido al Minoico Final IIIC por Taylour (1958: 147, lám. 15/10) parece corresponder al Minoico Final IIIB (Vagnetti, 1985: 826).

Otra opción sería incluir esta cerámica de Huelva dentro del Heládico Final IIIC:1 pues son varios elementos los que apuntan en este sentido. En primer lugar su pasta, que no parece egea, con una mezcla de marrón claro verdoso, gray-brown and greenish, con acabado en mate, que suele caracterizar a las producciones tanto del Heládico Final IIIC chipriota (Kling, 2000: 282) como a las filisteas iniciales del Heládico Final IIIC:1 (Dothan y Zukerman, 2004: 31 n. 26, 35). El grosor de la pasta en el cuello y en la espalda, apuntan a que debe tratarse de una jarra de transporte, posible contenedor de líquidos, pues las jarras de estribo pequeñas suelen tener las paredes finas.

En segundo lugar es orientativa la decoración. Se trata de al menos dos triángulos rellenos de color negro, unidos por sus vértices del lado menor, que deben conformar un motivo de estrella de 6 u 8 puntas, dos de los cuales deben coincidir con las asas verticales de la jarra de estribo.

Este motivo de triángulos rellenos de color negro no es nada frecuente pues en los principales catálogos de cerámica micénica (Furumak, 1972; Mountjoy, 1993 y 1999) o minoica (Kanta, 1980; Betancourt, 1985) no se observan ejemplos totalmente exactos, pero sí recoge Furumak (1941/1972: fig. 44/49) la presencia de triángulos rellenos de pintura en cerámicas del Micénico Final IIIC:1b.

En este sentido, se aproxima a algunas decoraciones del Heládico Final IIIC:1, como en un fragmento de espalda de una pyxis de Ekron que muestra triángulos alternos rellenos unos de negro y otros de líneas cruzadas formando retícula (Dothan y Zukerman,
2004: 26 tabla 13, 28, 27 fig. 30/9). Tanto las pyxis como las stirrup jars no son muy frecuentes en estas series del Heládico Final IIIC:1 (Killebrew, 2000: 243, 241 fig. 12.d.10), con lo que no hay muchos ejemplos de comparación, aunque Dothan y Zukerman (2004: 29 fig. 31/1-4) presentan varios ejemplos de Ekron de los niveles VIB y VIA (fig. 8).

Semicírculos rellenos de negro, en vez de triángulos, los encontramos en una crátera de Ekron del nivel VIIB, que además tiene la particularidad en un caso de ir acompañado de un elemento vegetal, no muy frecuente, concretamente una palma (Dothan $\mathrm{y}$ Zukerman, 2004: 16, 17 fig. 16/1, 41).

En general, estas cerámicas del Heládico Final IIIC:1b son atribuidas al Heládico Final IIIC Middle (Warren y Hankey, 1989: 166-167; Mountjoy, 1993: 175), mientras que Dothan y Zukerman (2004: 6, 43; com pers. P. Mountjoy y E. French) consideran que comenzaron a fabricarse ya con patrones decorativos complejos en el Heládico Final IIIC Early 2, durante los reinados de Ramses IV y Ramses VI, ca. 11531136 a.C. (Kitchen, 1996).

Teniendo en cuenta que estas cerámicas del Heládico Final IIIC:1b son casi idénticas, tanto las localizadas en Chipre (Kling, 1989) como las presentes en Canaan (Killebrew, 2000: 243), se ha sugerido como nombre también para estas producciones el de White Painted Wheelmade III (Aström, 1972: 271280; Killebrew, 2000: 234).

Su elaboración se ha considerado bien resultado de ceramistas egeos desplazados al Levante o bien de chipriotas experimentados en tecnología cerámica egea que se instalaron en el Levante (Cagne, 2006-07: 109).

La presencia de cerámica filistea en la ruta hacia Occidente se ha detectado en Mozia (Sicilia), concretamente un fragmento bícromo a partir del 1100-900 AC (Nigro, 2016: 355-356 fig. 19).

Ya en el Mediterráneo Occidental, la presencia de cerámica filistea también se documenta en Cerdeña, pues en Sulki, isla de Sant Antioco del extremo suroeste de la isla, se localizaron en la campaña de excavaciones de 2005 hasta tres fragmentos cerámicos con bandas horizontales paralelas del Heládico Final IIIC de un mismo recipiente que han sido atribuidos a un recipiente filisteo del siglo XI AC asignable quizás a una cylindrical bottle, a un horn-shaped vessel o bien a una gourd-shaped jar (Bartoloni, 2008: 1595, 1596 fig. 1, 1597 fig. 2a-c).

Por otra parte, también en Cerdeña, concretamente procedente de la necrópolis noroccidental de Neapolis, en el golfo de Oristano, en el extremo opuesto a Tharros, se localizó una imitación en miniatura de 14 $\mathrm{cm}$ de la cara de un sarcófago filisteo que fecha hacia el siglo XI AC (Bartoloni, 1997: 99 fig. 1, 102 y 1998; contra, Acquaro, 1998). 

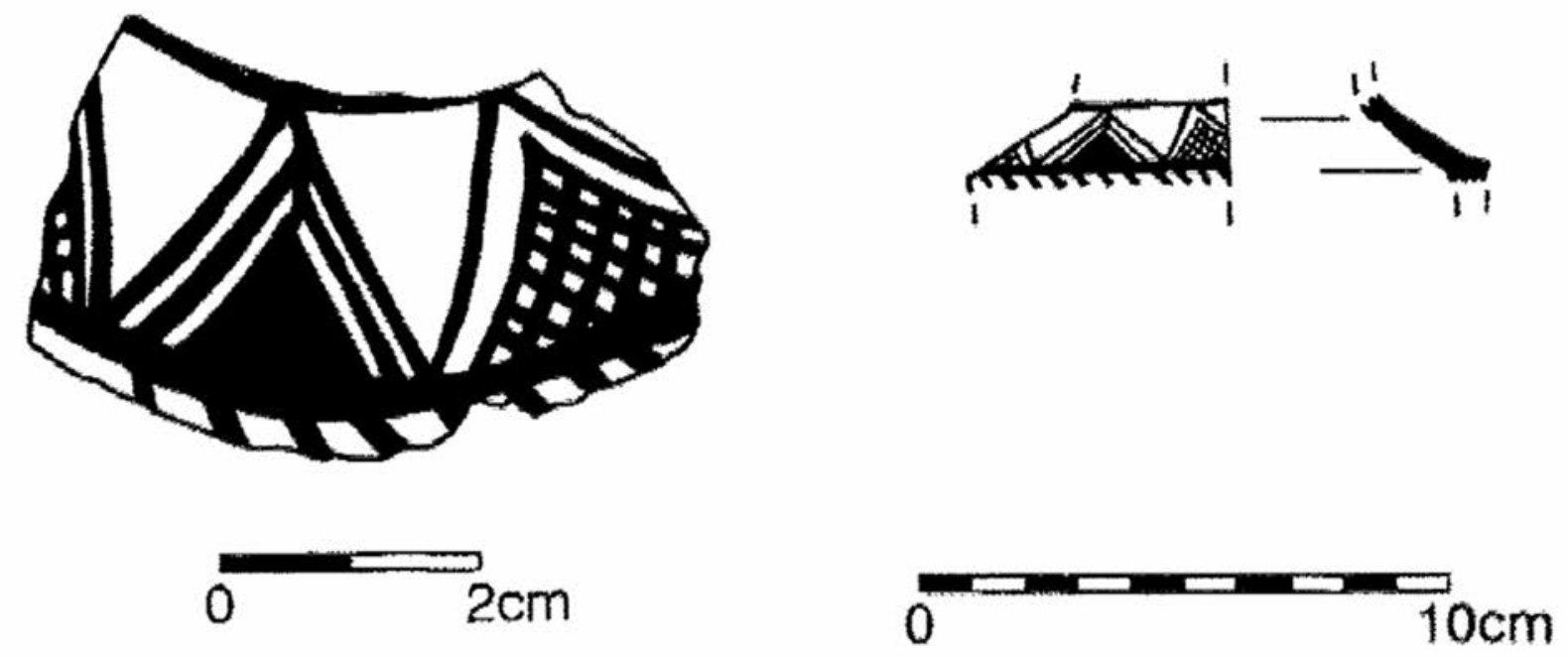

Figura 8. Píxide del Heládico Final IIIC:1, de Ekron que muestra triángulos alternos rellenos unos de negro y otros de líneas cruzadas formando retícula (Dothan y Zukerman, 2004: 27 fig. 30/9).

En cerámicas correspondientes al Heládico Final III, en la fase del Heládico Final IIIC Middle, del Close Style, hay motivos rellenos de negro en fondos de un box (Mountjoy, 1999: 1066, 1065 fig. 436/254) y conocemos algún triángulo relleno de negro alrededor del cuello en un alabastrón (Mountjoy, 1999: 1068, 1067 fig. 437/261).

En el Heládico Final IIIC Late, 1070-1050 a.C. (Mountjoy, 1998: 46, tabla 1), aparecen en la espalda, junto al cuello, de una jarra de cuatro asas -four handled jar- (Mountjoy, 1999: 393, 392 fig. 137/78). No obstante, más próximo a la pieza analizada, quizás sea un alabastrón de Elis, región occidental del Peloponeso, con triángulos rellenos de negro alrededor del cuello bordeados por un punteado -solid black triangles, dot fringed- (Mountjoy, 1999: 395, 394 fig. 138/85) (fig. 9).

Tanto si interpretamos la cerámica hallada de Huelva a partir del Heládico Final IIIC Early 2, durante los reinados de Ramses IV y Ramses VI, ca. 1153-1136 AC y el Heládico Final IIIC Middle hasta el 1070 AC, dentro de un eje con Fenicia y Chipre, bien como una jarra de estribo o stirrup jar del Minoico Final IIIC fechable entre el 1190-1070 AC, o incluso si la vinculamos al Heládico Final IIIC Late, 1070-1050 AC, en relación al Peloponeso Occidental, nos marcan la segunda mitad del siglo XII o primera mitad del siglo XI AC, coetáneos al Horizonte Formativo de Huelva, 1200-1000 AC (Gómez Toscano, 2013: 88 fig. 2), o el Bronce Final IIC, 1150-1050 AC (Mederos, 1996: 98 tabla 2 y 1997: 77 tabla 2; Torres, 2008: 77), siendo indicativo de la importancia de Huelva como puerto de comercio con el Mediterráneo Oriental.

\section{CONCLUSIONES}

A partir del 1153 AC, justo a la muerte de Ramsés III, debieron reanudarse los contactos con cierta intensidad hacia el Mediterráneo Occidental, cuando las ciudades de la costa filistea y libanesa ganaron autonomía de Egipto, a la vez que se intensificaba la acción de los mercaderes de las ciudades chipriotas. Esta etapa fue coetánea con el Hierro-Iron Age IB de Palestina, 1140-980 AC (Bruins, van der Plicht y Mazar, 2003: tabla S2).

En Chipre corresponde al Chipriota Final IIIB (Iacovou, 1989: 54), ca. 1150-1050 AC, y la ciudad más poderosa era el reino de Pafos en el Suroeste de la isla. Allí se encontraba el rico templo de AfroditaAstarté, donde se practicaba la prostitución sagrada y era una escala habitual de los marinos, "Afrodita, partió para Pafo de Chipre, donde tiene su templo y su altar, siempre lleno de ofrendas" (Hom., Od., VIII, 362-363). Del poderío naval chipriota queda constancia que el rey Cíniras Kinýras prometió 50 naves para el ataque contra Troya, pero finalmente sólo les envió una al mando del hijo de Migdalion (Apol., Epit., III, 9). El otro gran núcleo urbano fue la ciudad de Kition en el Sureste de la isla (Karageorghis, 1976).

Desde el último cuarto del siglo XII AC (Tsirkin, 1995: 65, 81 y 2005), o quizás mejor en su última década, empezaron a instalarse las primeras fundaciones de ciudades fenicias en el Mediterráneo, que pueden vincularse con las campañas de Tiglath-pileser I, Tukultī-apil-Ešarra, 1113-1076 AC (Jeffers, 2013: 188 tabla 2), cuyas expediciones llegaron hasta Arwad, en el Mediterráneo, situando a toda la cuenca siria y libanesa del río Orontes bajo su área de influencia, y exigiendo a pagar tributo a los puertos fenicios de Arwad, 


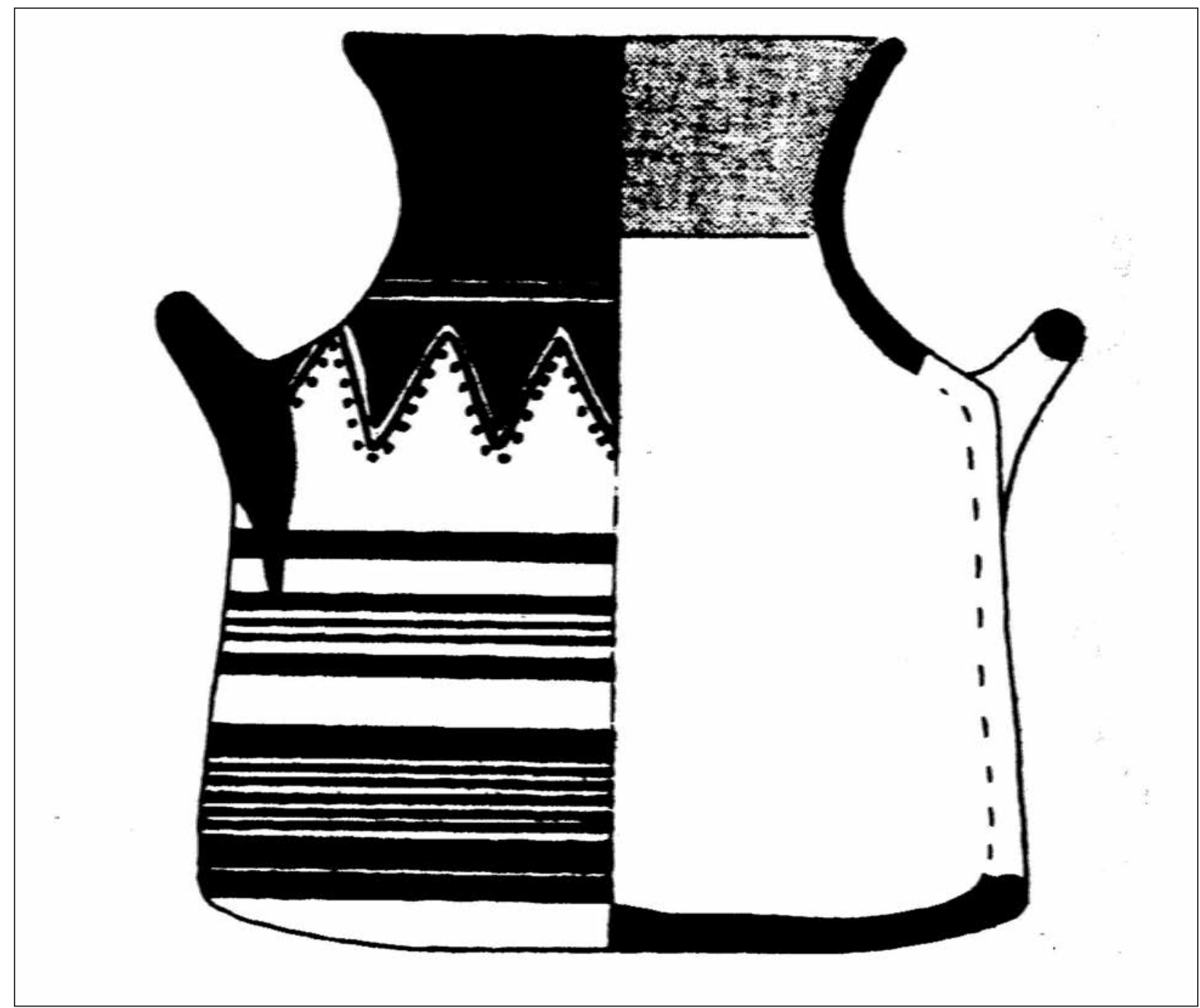

Figura 9. Alabastrón de Elis (Peloponeso), con triángulos rellenos de negro alrededor del cuello bordeados por un punteado (Mountjoy, 1999: 394 fig. 138/85).

Gubal-Biblos y Sidón (Pritchard 1955; ANET 274275). Arwad pasó probablemente a ser dependencia asiria pues después de conquistar Amurru y recibir el tributo de todos los reyes locales, Tiglath-pileser I navegó desde Arwad hasta Samuru, visitó Biblos y Sidón, y cazó un animal marino que denomina nahiru o caballo del mar (Grayson, 1991: RIMA II, A.0.87.3, 16-25; Yamada, 2005: 33-34, 52 tabla 3). La campaña de Tiglath-pileser I fue poco después de su décimo año de reinado, lo que nos sitúa ca. 1104 AC.

El incremento de la tributación y en particular la creciente demanda de materias primas de lujo por el imperio asirio debieron ser factores que estimularon el proceso, y en particular, la necesidad de obtener marfil de elefante africano y púrpura (Mederos y Escribano, 2015). Desde el Bronce Final se debió incrementar el abastecimiento de marfil de elefante, parte del cual tuvo que obtenerse del Norte de África, pues el marfil de hipopótamo pasó a tener un peso secundario (Fischer, 2007; Gachet-Bizollon, 2007), y este mismo fenómeno sucedió con el marfil de los inicios de la Edad del Hierro, cuando ya parece que escaseaban los elefantes asiáticos en la costa del Levante y tuvo que obtenerse la mayor parte del suministro en África.

Según las fuentes escritas, aunque falta una confirmación arqueológica, la fundación fenicia más antigua parece ser el santuario de Melqart en Gadir la cual se sitúa habitualmente en el 1106 a.C., 80 años después de la caída de Troya, según recoge Veleyo Patérculo (Hist. Rom., I, 2, 3), pero algún autor local como Mela retrotrae su antigüedad, "el templo de Hércules Egipcio (...) Los tirios lo construyeron (...) desde la época de Troya" (Mel., III, 6, 46), ca. 1186 a.C. según los cálculos de Timeo en el siglo IV-III AC (Mederos, 2007: 97-98 tabla 1), o al menos sugiere la frecuentación del lugar desde mediados del siglo XII AC.

Previamente habría habido intentos de fundación de santuarios en las localidades de Sexi (Almuñécar) y Onuba (Huelva) (Str., III, 1, 5). La situación estratégica de Onuba frente al estuario marino del 
Guadalquivir, estaba en relación con su mayor proximidad con el complejo minero de Riotinto, pues el río Tinto era navegable $28 \mathrm{~km}$. entre Onuba y Niebla.

Otra opción que se ha planteado es una posible fundación filistea de Gadir, junto a Gadara en Cerdeña, en torno al 1000 a.C. en Cerdeña, Gadara, y la Península Ibérica, Gadir (Garbini, 1997: 83-84, 123, 125-126). El término $g d r$ no está documentado como un lexema fenicio-púnico, y sí en cambio en el hebreo gdr, gader, el cual además se trata de un topónimo que se concentra en el Sur de Palestina (Isserlin, 1957), Gadara en el Trasjordán, que considera la más poderosa fortaleza de la región (Pol., V , 71), y en particular en el territorio de la tribu de Judá, recogidas en el libro de Josué, donde se mencionan cuatro ciudades con esta raíz: Gederah (Jos., XV, 36), Gederot, Gedor (Jos., XV, 41 y 58), Géder (Jos., XII, 13) y quizás Gedor (Cr., IV, 39), que correspondería a asentamientos filisteos fortificados durante la ocupación de la región de Judea.

La ruta marítima que pudieron utilizar fenicios o filisteos desde el Levante atravesaba todo el Mediterráneo, isla de Chipre, Patara (Licia), isla de Rodas, isla de Astipalea de Cárpatos, Ténaro (Laconia), Lilibeo en la isla de Sicilia y Cáralis en Cerdeña (Plin., N.H., II, 108, 243). Hubo una fundación fenicia de un santuario en Rodas (Diod., V, 58, 2) donde Cadmo, qdm, el oriental, uno de los hijos de Agenor, rey de Tiro y Sidón (Apol., II, 1; Hrdt., II, 2), "levantó en la isla un santuario en honor de este dios [Poseidón] y dejó allí algunos fenicios para su cuidado". También pudo existir una antigua fundación o dependencia fenicia, reconquistada a mediados del siglo X AC en Kition o Citium, sur de Chipre, según Flavio Josefo (C. Apion, I, 18, 119; Ant. Iud., VIII, 5, $3,146)$, pues el rey de Tiro, "Hiram (...) Dirigió una campaña contra los [k]iticeos que no pagaban los tributos y no regresó hasta haberlos sometido de nuevo a su dominio", aunque autores como Lipinski (2004: 42 n. 23; Gilboa, 2013: 317) creen que se trata de una referencia a Akko. Finalmente, por Tucídides (VI, 2, 6) sabemos de la presencia fenicia en Sicilia antes de los griegos.

La ruta desde del sur de Chipre hasta el sur de Creta serían 5 días, más 7 días de Creta a Malta, 1.5 días de Malta a Pantelaria, 1.5 días de Pantelaria hasta Cartago y 2 días de Cartago al sur de Cerdeña (Díes Cusí, 2005: $66-68,73)$, que suman 17 días. Si el puerto de salida era Tiro hacia sur de Chipre serían 2 días más (Díes Cusí, 2005: 66).

La conexión entre Cerdeña y la Península Ibérica era a través del pelagos sardonion según Eratóstenes (en Plin., N.H., III, 5, 75), pues entre "todo el mar que se halla entre la boca del Océano y Cerdeña, le dice Sardo", si se acepta una navegación directa de Cerdeña hacia las Islas Baleares, o en sentido inverso, aunque otros autores la rechazan proponiendo sólo una de cabotaje por el Sur de Francia, Cataluña, Valencia y finalmente el Sureste ibérico (Ruiz-Gálvez, 2013: 269270; Botto, 2011: 54 fig. 2 y 2013: 198 fig. 1), llegándose a defender que fue la única ruta posible hasta época romana (Guerrero Ayuso, 2004: 147 y 2005: 97, 109, 113, 133 fig. 5b).

Esta ruta se hacía desde el sur de Cerdeña hasta Cádiz en 28 días, desglosable en 8 (6) días hasta Ibiza, 8 días de Ibiza a Cabo de Gata (Almería), 10 días de Cabo de Gata al Estrecho de Gibraltar y 2 días de Gibraltar a Gadir. El trayecto era más rápido en dirección Oeste a Este, de Gadir a Cerdeña, con 14 días, 2 hasta el Estrecho, 8 desde Gibraltar hasta Ibiza y 4 días de Ibiza a Cabo de Garde en Cerdeña. Si fuera hasta Huelva habría que sumar 2 días más (Díes Cusí, 1994: 326-328 y 2005: 73-74). Este trayecto de ida de 28 días desde Cerdeña es reducido a 10 días y 10 noches con una media de 3.5 nudos por Arnaud (2005: 158), apoyándose en los 1.250.000 pasos que señala Plinio de Caralis a Gades (Plin., N.H., II, 108, 243), si bien nos parece más razonable los tiempos calculados por Díes Cusí (fig. 10).

La otra alternativa era una ruta costera africana partiendo de Cartago, que seguiría por la costa argelina hasta Hippo Regia, para ir ganando altitud hasta alcanzar Ibiza y desde allí dirigirse a la Península Ibérica (Guerrero Ayuso, 2005: 112, 133 fig. 5b), evitando la intermediación sarda. Esta ruta se ha estimado en unos 35-40 días por Díes Cusí (1994: 327), pero también ha indicado la dificultad de navegar a partir de Argel y la necesidad de dirigirse hacia Ibiza. Por otra parte, debido a la corriente contraria entre 12 nudos habría de separarse de la costa para realizar singladuras diurnas aprovechando las brisas costeras y buscando por la noche abrigo, pero estos puntos de refugio escasean en la costa argelina, lo que apunta a que se debió potenciar la conexión marítima sarda. No obstante, autores como Celestino (2014: 80) la proponen como ruta de conexión en el siglo IX AC entre Cartago y Utica con Gadir.

Sumando los 19 días al alcanzar el sur de Cerdeña, y los 28 días de Cerdeña hasta Gadir, serían 47 días en el viaje que atravesaría el Mediterráneo desde las ciudades levantinas, siempre contando con condiciones favorables náuticas y no cuantificando las escalas en la ruta.

En esta ruta mediterránea que partiría de Fenicia o Filistia, pasando por el Sur de Chipre, debió llegar esta jarra de transporte, conteniendo algún tipo de bebida, cuya pasta marrón claro verdoso con acabado en mate sugiere bien producciones filisteas iniciales del Micénico Final IIIC:1b, que comenzaron a fabricarse ya con patrones decorativos complejos en el Heládico Final IIIC Early 2, durante los reinados de Ramses IV y Ramses VI, ca. 1153-1136 AC y continuaron durante el Heládico Final IIIC Middle hasta el 1070 AC. Una segunda opción es que se tratase de 


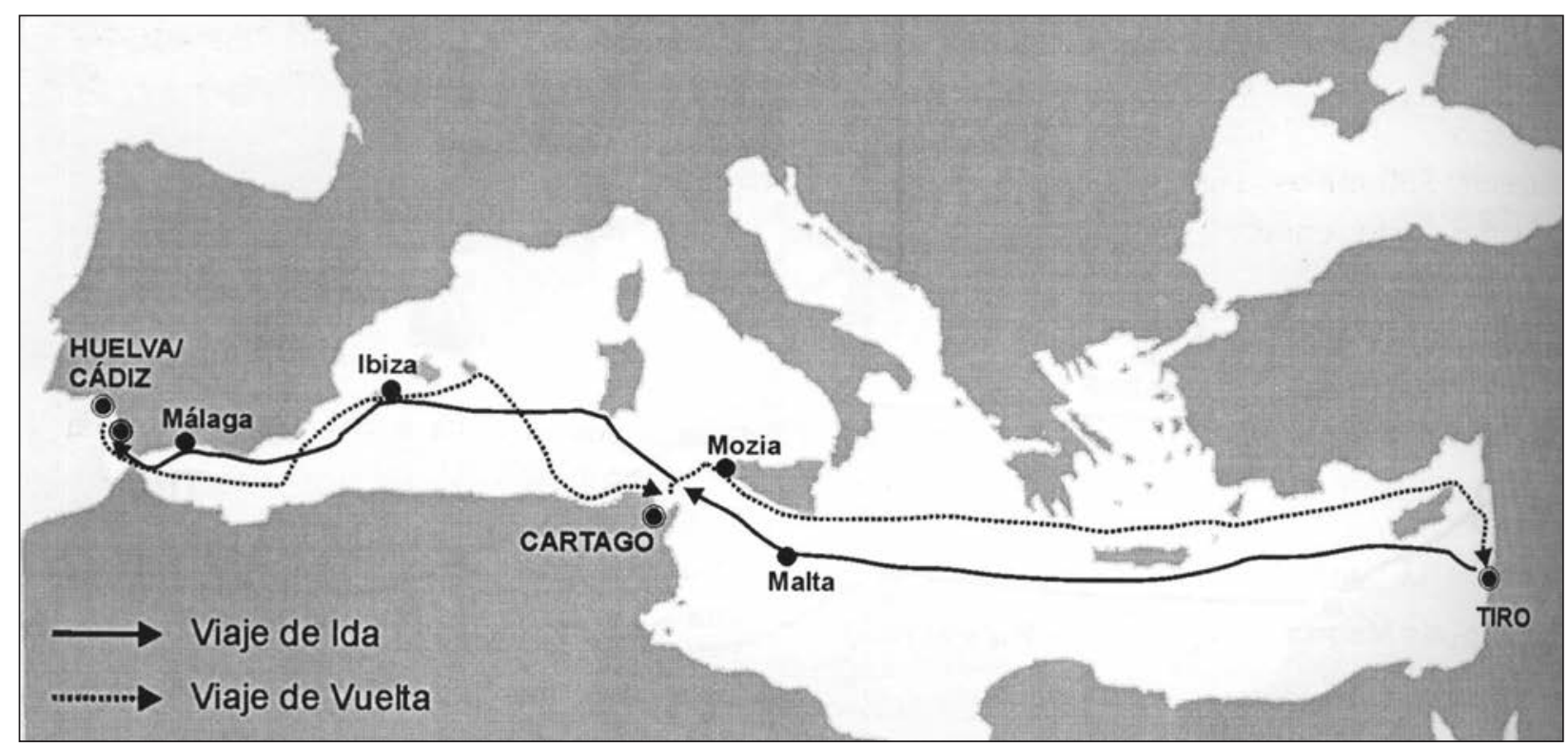

Figura 10. Ruta de navegación entre Tiro con Gadir/Cádiz y Onoba/Huelva, haciendo escala a la vuelta en Mozia (Díez Cusí, 2005: 72 fig. 9).

una jarra de estribo o stirrup jar del Minoico Final IIIC fechable entre el 1190-1070 AC. Una tercera opción sería relacionarla con el Heládico Final IIIC Late, 1070-1050 AC, todas ellas coetáneas al Bronce Final IIC, 1150-1050 AC.

\section{BIBLIOGRAFÍA}

Amo y de la Hera, M. del (1976): "Dos factorías romanas de salazón. 1. Factoría en la calle Palos". Restos materiales de la población romana de Onuba. Huelva Arqueológica, 2: 25-43.

Apolodoro [Apollodorus] (1921): The Library. I-II. J.G. Frazer (ed.). The Loeb Classical Library. G.P. Putnam's Sons-William Heinemann. New YorkLondon.

Apolodoro (1985): Biblioteca. Libros I-II. Trad. M. Rodríguez de Sepúlveda. Biblioteca Clásica Gredos, 85. Gredos. Madrid.

Acquaro, E. (1998): "Su un presunto frammento di sarcofago filisteo in Sardegna”. Studi di egittologia e di antichità puniche, 17: 47-53.

Arnaud, P. (2005): Les routes de la navigation antique. Itinéraires en Méditerranée. Errance. Paris.

Åström, P. (1972): The Late Cypriote Bronze Age. Architecture and Pottery. The Swedish Cyprus Expedition, IV. 1C. Lund.

Balensi, J. (2004): "Relativité de Phénoméne Mycecénien à Tell Abou Hawam: un 'ProtoMarketing'?”. En J. Balensi, J.Y. Monchambert y S. Müller (eds.): La céramique mycénienne de l'Egée au Levant. Travaux de la Maison de l'Orient et de la Méditerranée, 4. Lyon: 141-181.
Bartoloni, P. (1997): "Un sarcofago antropoide filisteo da Neapolis (Oristano - Sardegna)". Rivista di Studi Fenici, 25: 97-103.

Bartoloni, P. (1998): “Ancora su un sarcofago antropoide filisteo da Neapolis (Sardegna)". Rivista di Studi Fenici, 26: 139-142.

Bartoloni, P. (2008): "Nuovi dati sulla cronologia di Sulky”. En J. González, P. Ruggeri, C. Vismara y R. Zucca (eds.): L'Africa Romana XVII (1). Le ricchezze dell'Africa. Risorse, produzioni, scambi (Sevilla-Siviglia, 2006). Carocci Editore. Roma: 1595-1606.

Belén, $\mathrm{M}^{\mathrm{a}}$; Fernández-Miranda, M. y Garrido, J.P. (1977): "Los orígenes de Huelva. Excavaciones en los cabezos de San Pedro y La Esperanza". Huelva Arqueológica, 3: 5-375.

Betancourt, P. (1985): The History of the Minoan Pottery. Princeton University Press. Princeton.

Biblia de Jerusalén (1971/1994): Biblia de Jerusalén. J.A. Ubieta (ed.). Alianza Editorial-Desclée de Brouwer. Madrid-Bilbao.

Botto, M. (2011): "Interscambi e interazioni culturali fra Sardegna e Peninsola Iberica durante i secoli iniziali del I millennio a.C.”. En M. Álvarez MartíAguilar (ed.): Fenicios en Tartessos: nuevas perspectivas (Málaga, 2008). British Archaeological Reports, International Series, 2245. Oxford: 33-67.

Botto, M. (2013): "Fenicios, nurágicos y tartesios: modalidad y finalidad del encuentro entre gentes y culturas diversas en el paso del Bronce Final al Hierro I". En J. Campos y J. Alvar (eds.): Tarteso. El emporio del metal (Huelva, 2011). Almuzara. Córdoba: 197-210. 
Bruins, H.J.; Plicht, J. van der y Mazar, A. (2003): " ${ }^{14} \mathrm{C}$ Dates from Tel Rehov: Iron-Age Chronology, Pharaohs, and Hebrew Kings". Science, 300 (5617): 315-318. www.sciencemag.org/ cgi/content/full/300/5617/315/DC1 tables S1-S2.

Cabrera Bonet, P. (1988-89): "El comercio foceo en Huelva: cronología y fisionomía". Huelva Arqueológica, 10-11: 41-100.

Cagne, L. (2006-07): "The Problem of Regional Variation of Mycenaean IIIC:1 Pottery: The View from Cyprus". Scripta Mediterranea, 27-28: 105-111.

Celestino Pérez, S. (2014): Tarteso. Viaje a los confines del Mundo Antiguo. Trébede. Madrid.

Coldstream, J.N. (1982): “Discusión” en B.B. Shefton, "Greeks and Greek Imports in the South of the Iberian Peninsula. The Archaeological Evidence". En H.G. Niemeyer (ed.): Phönizier im Westen. Die Beiträge des International Symposiums über "Die phönizische Expansion im westlichen Mittelmeeraum” (Köln, 1979). Madrider Beiträge, 8. Philipp von Zabern. Mainz: 337-370.

Díes Cusí, E. (1994): “Aspectos técnicos de las rutas comerciales fenicias en el Mediterráneo Occidental (s. IX-VII a.C.)". Archivo de Prehistoria Levantina, 21: 311-336.

Díes Cusí, E. (2005): "Los condicionantes técnicos de la navegación fenicia en el Mediterráneo Oriental". En V. Peña, C. González Wagner y A. Mederos (eds.): La navegación fenicia: tecnología naval y derroteros (Madrid, 2002). Centro de Estudios Fenicios y Púnicos. Madrid: 55-84.

Diodoro de Sicilia (Diodorus of Sicily) (1961): Diodorus of Sicily III. Books IV,59-VIII. C.H. Oldfather (ed.). The Loeb Classical Library. Harvard University Press-William Heinemann. Cambridge-London.

Diodoro de Sicilia (2004): Biblioteca Histórica. Libros IV-VIII. Trad. J.J. Torres Esbarranch. Biblioteca Clásica Gredos, 328. Gredos. Madrid.

Dothan, T. y Zukerman, A. (2004): “A Preliminary Study of the Mycenaean IIIC:1 Pottery Assemblages from Tel Miqne-Ekron and Ashdod". Bulletin of the American Schools of Oriental Research, 333: 1-54.

Fischer, E. (2007): Ägyptische und ägyptisierende Elfenbeine aus Megiddo und Lachish. Inschriftenfunde, Flaschen, Löffel. AOAT, 47. Ugarit Verlag. Münster.

Furumark, A. (1941): The Mycenaean pottery: analysis and classification. Stockholm.

Gachet-Bizollon, J. (2007): Les Ivories d'Ougarit. Ras Shmra-Ougarit, 16. Paris.

Garbini, G. (1997): I filistei. Gli Antagonisti di Israele. Rusconi. Milano.
Gilboa, A. (2013): “À-propos Huelva: a reassessment of 'Early' Phoenician in the West'. En J. Campos y J. Alvar (eds.): Tarteso. El emporio del metal (Huelva, 2011). Almuzara. Córdoba: 311-342.

Gómez Toscano, F. (1990): “A propósito del fragmento de Geométrico Medio II del Museo Provincial de Huelva”. Cuadernos del Suroeste, 1: 1-6.

Gómez Toscano, F. (2008): "Cerámicas del Bronce Final en Huelva (1200-600 a.C.). Nueva tipología para explicar su amplitud cronológica". Homenaje a Pilar Acosta. Tabona, 16: 85-100.

Gómez Toscano, F. (2012): "El Bronce Final en el Bajo Guadiana: Huelva y la resolución de un paradigma”. En J. Jiménez Ávila (ed.): Sidereum Ana II. El río Guadiana en el Bronce Final. Consejo Superior de Investigaciones Científicas. Madrid: 309-326.

Gómez Toscano, F. (2013): “Contactos del Mediterráneo oriental en el suroeste de la Península Ibérica durante los siglos XIV-VIII a.C. ¿Marinos orientales o Fenicios atemporales". Onoba, 1: 79-98.

Gómez Toscano, F. y Campos, J.M. (2001): Arqueología en la ciudad de Huelva (1966-2000). Universidad de Huelva. Huelva.

Gómez Toscano, F. y Fundoni, G. (2010-11): "Relaciones del Suroeste con el Mediterráneo en el Bronce Final (siglos XI-X a.C.). Huelva y la isla de Cerdeña”. Anales de Arqueología Cordobesa, 2122: $17-56$.

González de Canales, F.; Serrano, L. y Llompart, J. (2004): El emporio fenicio precolonial de Huelva (ca. 900-770 a.C.). Biblioteca Nueva. Madrid.

Grayson, A.K. (1991): Assyrian Rulers of the Early First Millennium BC I (1114-859). The Royal Inscriptions of Mesopotamia, Assyrian Periods, 2. Toronto.

Guerrero Ayuso, V. (2004): "La marina de la Cerdeña nurágica”. Pyrenae, 35 (1): 117-155.

Guerrero Ayuso, V. (2005): "Las Islas Baleares en los derroteros del Mediterráneo Central y Occidental". En V. Peña, C. González Wagner y A. Mederos (eds.): La navegación fenicia: tecnología naval y derroteros (Madrid, 2002). Centro de Estudios Fenicios y Púnicos. Madrid: 85-133.

Herodoto [Herodotus] (1921): History. Books I-II. A.D. Godley (ed.). The Loeb Classical Library. G.P. Putnam's Sons-William Heinemann. New York-London.

Herodoto (1977): Historia. Libros I-II. Trad. C. Schrader. Biblioteca Clásica Gredos, 3. Madrid.

Homero [Homer] (1919): Odyssey. I-II. A.T. Murray (ed.). The Loeb Classical Library. G.P. Putnam's Sons-William Heinemann. New York-London. 
Homero (1982): Odisea. Trad. J. Manuel Pabón. Biblioteca Clásica Gredos, 48. Gredos. Madrid.

Iacovou, M. (1989): "Society and settlements in Late Cypriot III”. En E. Peltenburg (ed.): Early Society in Cyprus. Edinburgh University Press. Edinburgh: 52-59.

Isserlin, B.S.J. (1957): “On a Phoenician Spelling Mistake and the Question of 'Substratum' Influence". Sefarad, 17: 378-380.

Jeffers, J.A. (2013): Tiglath-Pileser I: a light in a 'Dark Age'. PhD. University of Pennsylvania. Philadelphia.

Josefo, F. [Flavius Josephus] (1926): The Life. Against Apion. I. H.S.J. Thackeray (ed.). The Loeb Classical Library. G.P. Putnam's Sons-William Heinemann. New York-London.

Josefo, F. (1994): Autobiografía. Contra Apión. Trad. M. Rodríguez de Sepúlveda. Biblioteca Clásica Gredos, 189. Madrid.

Josefo, F. [Flavius Josephus] (1926/1997): The Jewish War-De Bello Judaico. I. Books I-II. 2. Books IIIIV. 3. Books V-VII. H.S.J. Thackeray (ed.). The Loeb Classical Library. G.P. Putnam's SonsWilliam Heinemann. New York-London.

Josefo, F. (1999): La guerra de los judíos. Libros IVVII. Trad. J.Mª Nieto Ibáñez. Biblioteca Clásica Gredos, 264. Madrid.

Kanta, A. (1980): The Late Minoan III period in Crete: a survey of sites, pottery and their distribution. Studies in Mediterranean Archaeology, 58. Paul Åströms Förlag. Göteborg.

Karageorghis, V. (1976): View from the Bronze Age: Mycenaean and Phoenician discoveries at Kition. Dutton. New York.

Killebrew, A.E. (1998): "Mycenaean and Aegean Style Pottery in Canaan". En E.H. Cline y D. Harris-Cline (eds.): The Aegean and the Orient in the Second Millennium (Cincinnati, 1997). Aegaeum, 18. Liège: 159-169.

Kitchen, K.A. (1996): “The Historical Chronology of Ancient Egypt, A Current Assessment”. En K. Randsborg (eds.): Absolute Chronology. Archaeological Europe 2500-500 BC. Acta Archaeologica, 67: 1-13.

Kling, B. (1989): Mycenaean IIIC:1b and Related Pottery in Cyprus. Studies in Mediterranean Archaeology, 87. Paul Åströms Förlag. Göteborg.

Kling, B. (2000): "Mycenaean IIIC:1b and Related Pottery in Cyprus: Comments on the Current State of Research". En E.D. Oren (ed.): The Sea Peoples and their World. A Reassessment (Philadelphia, 1995). University of Pennsylvania Museum Monograph, 108. Philadelphia: 281-296.
Lipinski, E. (2004): Itineraria Phoenicia. Studia Phoenicia, 18. Orientalia Lovaniensia Analecta, 127. Uitgeverij Peeters. Leuven-Dudley, Ma.

Martín de la Cruz, J.C. (1989): "El Bronce en el valle medio del Guadalquivir". En $\mathrm{M}^{\mathrm{a}}$.E. Aubet (ed.): Tartessos. Arqueología Protohistórica del Bajo Guadalquivir. Ausa. Sabadell-Barcelona. pp. 121143.

Mederos Martín, A. (1996): "La conexión levantinochipriota. Indicios de comercio atlántico con el Mediterráneo oriental durante el Bronce Final (1150-950 AC)". Trabajos de Prehistoria, 53 (2): 95115. http://dx.doi.org/10.3989/tp.1996.v53.i2.394

Mederos Martín, A. (1997): "Nueva cronología del Bronce Final en el Occidente de Europa". Complutum, 8: 73-96.

Mederos Martín, A. (2006): "Fenicios en Huelva, en el siglo X AC, durante el reinado de Hîram I de Tiro". Spal, 15: 167-188. http://dx.doi.org/10.12795/spal. 2006.i15.08

Mederos Martín, A. (2007): "La crisis del siglo XII a.C. Pueblos del Mar y Guerra de Troya ca. 12151175 a.C.". Spal, 16: 93-153. http://dx.doi.org/ 10.12795/spal.2007.i16.06

Mederos Martín, A. (2012): "El final de Cogotas I y los inicios de la Edad del Hierro en el centro de la Península Ibérica (1200-800 AC)". En J. Morín y D. Urbina (eds.): El primer milenio a.C. en la Meseta central. De la longhouse al oppidum (Madrid, 2008). I. Primera Edad del Hierro. Audema. CD-Rom. Madrid: 73-107.

Mederos, A. y Escribano, G. (2015): Oceanus Gaditanus. Oro, púrpura y pesca en el litoral atlántico norteafricano y las Islas Canarias en época fenicia, cartaginesa y romana republicana. Thesaurus Arqueología, 3. Ediciones Idea. SevillaTenerife.

Mela, P. (1989): Corografía. Trad. C. Guzmán Arias. Universidad de Murcia. Murcia.

Mountjoy, P.A. (1993): Mycenaean Pottery: An Introduction. University of Oxford Committee for Archaeology, Monograph 36. University of Oxford Committee for Archaeology. Oxford.

Mountjoy, P.A. (1998): “The East Aegean-West Anatolian Interface in the Late Bronze Age: Mycenaeans and the Kingdom of Ahhiyawa". Anatolian Studies, 48: 33-67. https://doi.org/ $10.2307 / 3643047$

Mountjoy, P.A. (1999): Regional Mycenaean Decorated Pottery. Deutsches Archäologisches Institut. Verlag Marie Leidorf GmbH. Rahden.

Müller, W. (1997): Kretische tongefässe mit meeresdekor. Entwicklung und Stellung innerhalb der Feinen Keramik von Spätminoisch I B auf Kreta. 
Archäologische Forschungen, 19. Gerb. Mann Verlag. Berlin.

Niemeier, W.D. (1985): Die Palasttilkeramik von Knossos. Stil, chronologie und historischer context. Archäologische Forschungen, 13. Gerb. Mann Verlag. Berlin.

Nigro, L. (2016): "Mozia nella preistoria e le rotte Levantine: I prodromi della colonizzazione fenicia tra secondo e primo millennio a.C. nei recenti scavi della Sapienza". Scienze dell'Antichità, 22 (2): 339-362.

Plinio el Viejo (Pliny) (1967/1979): Natural History. 1. Prefatio. Libri I-II. H. Rackham (ed.). The Loeb Classical Library. Harvard University PressWilliam Heinemann. Cambridge, Mass.-London.

Plinio el Viejo (Pliny) (1967): Natural History. 2. Libri III-VII. H. Rackham (ed.). The Loeb Classical Library. Harvard University Press-William Heinemann. Cambridge, Mass.-London.

Polibio (1981): Historias. Libros $V-X V$. Trad. M. Balasch Recort. Biblioteca Clásica Gredos, 43. Madrid.

Polibio (Polybius) (2011): The Histories. III. Books 58. W.R. Paton (ed.), F.V. Walbank y C. Haricht (revised). The Loeb Classical Library, 138. Harvard University Press-William Heinemann. Cambridge-London.

Pritchard, J.B. (ed.) (1955): Ancient Near Eastern Texts Relating to the Old Testament (ANET). Princeton University Press. Princeton.

Rouillard, P. (1977): "Fragmentos griegos de estilo Geométrico y Corintio Medio en Huelva". En M $\mathrm{M}^{\mathrm{a}}$. Belén, M. Fernández Miranda y J.P. Garrido (eds.): Los orígenes de Huelva. Excavaciones en los cabezos de San Pedro y la Esperanza. Huelva Arqueológica, 3: 395-401.

Ruiz-Gálvez Priego, Mª.L. (2013): Con el fenicio en los talones. Los inicios de la Edad del Hierro en la cuenca del Mediterráneo. Bellaterra Arqueología. Barcelona.

Shefton, B.B. (1982): "Greeks and Greek Imports in the South of the Iberian Peninsula. The Archaeological Evidence". En H.G. Niemeyer (ed.): Phönizier im Westen. Die Beiträge des International Symposiums über "Die phönizische Expansion im westlichen Mittelmeeraum” (Köln, 1979). Madrider Beiträge, 8. Philipp von Zabern.. Mainz: 337-370.
Taylour, W. (1958): Mycenaean Pottery in Italy and Adjacent Areas. Cambridge University Press. Cambridge.

Torres Ortiz, M. (1998): “La cronología absoluta europea y el inicio de la colonización fenicia en Occidente. Implicaciones cronológicas en Chipre y el Próximo Oriente”. Complutum, 9: 49-60.

Torres Ortiz, M. (2008): “Los 'tiempos' de la precolonización”. En S. Celestino, N. Rafel y X.L. Armada (eds.): Contacto cultural entre el Mediterráneo y el Atlántico (siglos XII-VIII ANE): La Precolonización a debate. Escuela Española de Historia y Arqueología de Roma del CSIC. Serie Arqueológica, 11. Roma: 59-91.

Tsirkin, J.B. (1995): "Primera etapa de la colonización fenicia". Espacio, Tiempo y Forma. Serie II, Historia Antigua, 2: 61-83.

Tsirkin, J.B. (2005): "Fenicia y los cambios en Asia Anterior cerca 1200 a. de C. cuanto al problema del inicio de la historia fenicia”. En A. Spanò Giammellaro (ed.): V Congresso Internazionale di Studi Fenici e Punici (Marsala-Palermo, 2000). I. Università degli Studi di Palermo. Palermo: 19-22.

Tucídides (1992): Historia de la Guerra del Peloponeso. Libros V-VI. Trad. J.J. Torres Esbarranch. Biblioteca Clásica Gredos, 164. Madrid.

Vagnetti, L. (1985): “Ceramiche del Tardo Minoico III rinvenute in Italia". En M. Liverani, A. Palmieri y R. Peroni (eds.): Studi di paletnologia in onore di Salvatore M. Puglisi. Università di Roma 'La Sapienza'. Roma: 825-831.

Veleyo Patérculo, M. [Velleius Paterculus] (1924): Compendium of Roman History. Res gestae divi Augusti. Trad. F.W. Shipley. The Loeb Classical Library. William Heinemann-G.P. Putnam's sons. London-New York.

Veleyo Patérculo, M. (2001): Historia Romana. Trad. M $^{a}$.A. Sánchez Manzano. Biblioteca Clásica Gredos, 284. Madrid.

Warren, P. y Hankey, V. (1989): Aegean Bronze Age Chronology. Bristol Classical Press. Bristol.

Yamada, K. (2005): "From the Upper Sea to the Lower Sea'. The Development of the Names of Seas in the Assyrian Royal Inscriptions". Orient, Report of the Society for Near Eastern Studies in Japan, 40: 31-55. 
